\title{
História difícil e etnocentrismo: o ensino de história e o genocídio de Ruanda na web
}

\author{
Burdening History and ethnocetrism: the History teaching and Rwanda's \\ genocide on the web
}

Danilo Ferreira da Fonseca ${ }^{1}$
Geyso Dongley Germinari $^{2}$

\section{RESUMO}

A consciência histórica no mundo contemporâneo tem a função vital de instituir sentido temporal à vida humana, por meio de processos específicos de aprendizagem a consciência articula passado, presente e futuro numa mesma estrutura temporal que estabelece sentido histórico ao indivíduo e ao mundo. As mudanças temporais vividas e sofridas como instabilidade carecem de novos significados no curso do tempo, necessitam de sentido histórico para continuidade das atividades humanas cotidianas. As mudanças temporais que desestabilizam a vida podem ser traumáticas, hostis, amargas, tristes, pesadas, conflitivas, difíceis de serem vividas, aquilo que o historiador e didaticista alemão Bodo von Borries (2016) chama de Burdening History, que são histórias difíceis de serem ensinadas e aprendidas, porque carregam sentimentos fortes de culpa, vergonha e luto. Com base neste pressuposto, buscou-se contribuir com debate, a partir da reflexão acerca do ensino de História sobre Ruanda, particularmente acerca do chamado genocídio de Ruanda. O estudo analisou sítios da Web de divulgação de conteúdos históricos. É crescente a utilização da internet no ambiente escolar, tanto pelas crianças e jovens, quanto pelos professores.

Palavras-chave: Ensino de História. História difícil. Etnocentrismo. Genocídio de Ruanda.

\begin{abstract}
The historical consciousness in the contemporary world has the vital function of instituting temporal sense to human life, through specific processes of learning, consciousness articulates past, present and future in the same temporal structure that establishes historical sense to the individual and to the world. The temporal changes lived and suffered as instability need new meanings in the course of time, they need historical sense for the continuity of daily human activities. The temporal changes that destabilize life can be traumatic, hostile, bitter, sad, heavy, conflicting, difficult to live, what the German historian and didaticist Bodo von Borries (2016) calls Burdening History, which are difficult stories to be taught and learned because they carry strong feelings of guilt, shame and mourning. Based on this assumption, we tried to contribute with the debate, from the reflection about the History teaching in Rwanda, particularly about the so-called Rwanda genocide. The study looked at historical content disclosure Web sites. The use of the internet in the school environment is growing, both by children and young people, as well as by teachers.
\end{abstract}

Keywords: History teaching. Burdening History. Ethnocentrism. Rwandan genocide.

1 Doutor em História Social/ PUC-SP. Professor do departamento de história da Universidade Estadual do Centro-Oeste (UNICENTRO). E-mail: daniloffonseca@gmail.com.

2 Doutor em Educação/UFPR. Professor do Departamento de História e dos Programas de Pós-Graduação em Educação e História da Universidade Estadual do Centro-Oeste (UNICENTRO). E-mail: geysog@gmail.com. 


\section{Considerações Iniciais}

Nos últimos quinze anos, desde a promulgação da lei 10.639/03, o ensino de História da África mudou significativamente, dando-lhe um maior espaço em propostas curriculares, materiais didáticos e prática de ensino-aprendizagens em todos os níveis educacionais. "As proposições da Lei 10.639 exigem revisões não apenas das interpretações da trajetória histórica dos negros africanos e afro-brasileiros, até então representada pela via quase exclusiva da desigualdade e intolerância, geradora de inversões do significado de ser negro no Brasil mas das práticas de ensino [...]" (CAMPOS, 2004, p. 41).

Dessa forma, histórias que passaram anos silenciadas e tratadas como sendo de menor importância, ou até como uma mera história coadjuvante, passaram a ter um destaque maior, dando voz a sujeitos históricos africanos e afro-brasileiros que até então possuíam a sua história negada nos diferentes níveis de ensino e pesquisa na área de História no Brasil.

No entanto, em muitos casos, o despreparo e falta de formação inicial e continuada para o tratamento de tais temáticas frente às especificidades que os processos históricos africanos possuem, fez com que a história da África fosse tratada no espaço escolar de modo enviesado, em uma concepção historiográfica e histórica excessivamente eurocêntrica, a qual foi considerada a normativa para área durante mais de um século, fazia - e ainda faz - com que a perspectiva e a historicidade dada aos sujeitos históricos de origem africana sejam tratados como de segundo plano.

Essa perspectiva etnocêntrica focada excessivamente no mundo e no homem europeu busca reforçar constantemente uma suposta superioridade da sociedade e da história da Europa (em diferentes âmbitos como cultural, econômico, político e até biológico!), o que permeia ideologicamente a constituição da sociedade contemporânea, indo muito além de questões que envolvem a história e o ensino de História.

A partir de tal constituição, ainda é bastante presente no senso comum a visão de que os africanos e a África seriam o ambiente do "selvagem", do "não civilizado", ou até "do pecado", o que traz um desafio para o ensino de algumas temáticas que envolvem a história de tal complexa territorialidade, em que, dependendo da forma que o professor desenvolve determinada temática, pode reforçar estereótipos e marginalizar ainda mais tais sociedades em nosso tempo presente. 
Uma temática de enorme sensibilidade (e tão necessária quanto) que pode tanto corroborar quanto combater tal questão é o genocídio de Ruanda de 1994, que, para além da sua dimensão histórica, possibilita uma reflexão fundamental para o mundo contemporâneo. Em um debate promovido pelo jornal britânico The Guardian em 2009, e escrito pela jornalista Ellie Levenson, acerca da necessidade e obrigatoriedade de se ensinar o genocídio de Ruanda nas escolas britânicas, ${ }^{3}$ David Russell (diretor da ONG SURF) coloca o ensino da história recente de Ruanda como uma possibilidade de reflexão acerca da deficiência do esforço e compromisso coletivo internacional para impedir o acontecimento de novos genocídios pelo mundo, desde o Holocausto durante a Segunda Guerra Mundial. Ainda dentro desse debate, a professora de história britânica, Sam Hunt, afirma que "Ensinar o genocídio de Ruanda deveria ser parte compulsória de nosso currículo nacional"4 (LEVENSON, 2009), em que o genocídio se classifica como "uma vergonha em toda humanidade" 5 (LEVENSON, 2009). A professora ainda nos aponta que:

Precisamos aprender sobre isso por que isso é relevante hoje. Quando comecei a ensinar sobre o genocídio de Ruanda, poucos alunos já haviam ouvido falar sobre isso antes. A maioria nem tinha ouvido falar de Ruanda. Eles são obrigados a olhar para o Holocausto, e muitos deles acham que isso não poderia acontecer novamente, mas aconteceu - aconteceu há apenas 15 anos e está acontecendo agora, em nosso tempo de vida, em Darfur (LEVENSON, 2009) ${ }^{6}$.

De modo substantivo, o genocídio de Ruanda se constituiu entre abril e julho 1994 quando uma parte significativa da população local de origem Hutu pegou em armas e, sendo direcionada por uma intensa organização e propaganda de grupos extremistas hutus, assassinaram algo entre 500 mil e um milhão de tutsis e hutu moderados, produzindo um dos maiores genocídios do século XX.

Tal temática, bastante sensível dentro de uma perspectiva humanística que entende a unidade humana a partir da pluralidade, deveria ser entendida dentro do conceito de História Difícil, que, na perspectiva do historiador e didaticista alemão Bodo von Borries (2016), significa histórias hostis, amargas, tristes, pesadas, conflitivas pela qual passam grupos e sociedades, tais histórias causam culpa, vergonha e luto no âmbito individual e coletivo, por isso, são mais difíceis de serem ensinadas e aprendidas, o Holocausto e o genocídio de Ruanda são bons exemplos de Histórias Difíceis.

3 Matéria disponível no site: https://www.theguardian.com/education/2009/mar/31/rwanda-genocide, acesso no dia 27/09/2018.

4 No original: "Teaching the Rwandan genocide should be a compulsory part of our national curriculum"

5 No original: "a shame on all humanity".

6 No original: We need to learn about it in terms of why it is relevant today. When I started teaching about the Rwandan genocide, very few of the students had heard of it before. Most hadn't even heard of Rwanda. They are soused to looking at the Holocaust, and many of them think that it couldn't happen again, but it has happened - it happened just 15 years ago and it's happening right now, in our life time, in Darfur." 
Para refletirmos acerca do ensino de História sobre Ruanda e o seu caráter de uma história etnocêntrica e também de uma História Difícil, a presente investigação analisou os sítios da web, Uol Educação e Brasil Escola, voltados para divulgação de conteúdos históricos. A opção justifica-se pelo crescente uso da internet entre as crianças e jovens em suas atividades escolares bem como entre os professores na organização e na prática das aulas.

No entanto, antes de entrarmos diretamente na análise dos dados levantados pela pesquisa e no desenvolvimento metodológico, precisamos compreender melhor os conceitos que envolvem o etnocentrismo e também a História Difícil e sua relação com a aprendizagem histórica dos jovens, os quais são os pilares da argumentação que propomos aqui, assim como precisamos deixar mais claro o próprio processo histórico que envolve o genocídio de Ruanda.

\section{Ruanda e Genocídios: uma História Difícil?}

A constituição da sociedade contemporânea do pós Segunda Guerra Mundial (1939 1945) foi marcada pela formação da Organização das Nações Unidas, a ascensão dos Estados Unidos como maior potência do ocidente, o que está diretamente correlacionado também com fim dos tradicionais impérios europeus que dominavam quase todo 0 continente africano e parte do asiático, os quais conquistaram a independência gestando dezenas de novos países.

O século $X X$ tem no seu cerne uma reflexão que envolve diretamente os processos históricos que circundam o Holocausto, tendo em vista que o extermínio de milhões de pessoas que, dentro da concepção nazista, não condiziam com as supostas características superiores dos arianos como é o caso de deficientes, ciganos, negros e principalmente judeus, desvelou uma obscura faceta do racionalismo moderno quando este não está a serviço do pluralismo humano. Assim, a formação da ONU e de nossa sociedade estaria (ou pelo menos deveria estar) compromissada com uma sociedade mais plural, evitando a todo custo a repetição dos crimes ocorridos durante a Segunda Guerra Mundial, principalmente o Holocausto e crimes contra a humanidade.

Nas palavras de Habermas (1999, p. 1):

A fundação da ONU e sua Declaração Universal dos Direitos Humanos, bem como a ameaça de punição à guerra de ataque e aos crimes contra a humanidade - com a conseqüência de uma limitação sem muita convicção do Princípio da Nãointervenção -, foram respostas necessárias e corretas às experiências moralmente significativas do século, ao desencadeamento totalitário da política e ao holocausto. 
A visão de que existiria uma nova forma de crime, que seria contra a humanidade como um todo, só foi possível a partir de uma nova elaboração histórica acerca do que seria uma unidade humana. Segundo Fábio Konder Comparato (2003, p. 4), ela seria:

\begin{abstract}
[...] a parte mais bela e importante de toda a História: a revelação de que todos os seres humanos, apesar das inúmeras diferenças biológicas e culturais que os distinguem entre si, merecem igual respeito. Como únicos entes no mundo capazes de amar, descobrir a verdade e criar a beleza. E o reconhecimento universal de que, em razão dessa radical igualdade, ninguém - nenhum indivíduo, gênero, etnia, classe social, grupo religioso ou nação - pode afirmar-se superior aos demais.
\end{abstract}

No entanto, a construção histórica de tal percepção de humanidade se deu a partir de um longo processo histórico, que culmina apenas no século XX a percepção de que deveria existir uma plena igualdade e liberdade entre homens e mulheres, o que levantou uma potencial unidade humana sem precedentes. É a partir dessa concepção de humanidade e da experiência do Holocausto, segundo Comparato (2003), que a comunidade internacional elabora as concepções de crime de genocídio ${ }^{7}$ e também de crimes contra a humanidade ${ }^{8}$.

Diante de tais processos, o Ensino de História assume um papel fundamental para a nossa sociedade, com o dever de produzir reflexões e aprendizagens que possibilitem que tais histórias difíceis vinculadas a crimes contra a humanidade sejam uma forma de produzir uma consciência histórica mais ampla e plural, fugindo de concepções etnocêntricas e que cultivem o ódio pela diferença. Tal responsabilidade se demonstra ainda maior se temos em mente que uma parte significativa dos crimes cometidos pela humanidade no século $X X$ possui por trás concepções históricas e de processos históricos que são enviesadas para gestar justamente o ódio e legitimar o discurso histórico aos crimes cometidos.

Dessa forma, o ensino de história que produz reflexões sobre os processos de genocídio é fundamental para a construção de humanidade ampliada, e é nesse sentido que Bono von Borries (2016) nos traz as reflexões acerca da história difícil e que Rüsen (2001, 2006, 2009) reflete acerca da construção de uma consciência histórica a partir do Ensino de História e seu processo de aprendizagem.

No entanto, os esforços sistemáticos tanto no âmbito da política, quanto do Ensino da História não impediram que crimes contra humanidade ocorressem e, em alguns casos, até corroboraram com a organização e execução de genocídios. O compromisso estabelecido pela ONU de que "isto [o genocídio] não ocorra nunca mais", e que não mediria esforços para evitar fracassou. Tal fracasso se dá na medida em que os discursos que envolveriam

7 Crime de genocídio é comumente considerado como o assassinato deliberado de pessoas motivado por diferenças étnicas, nacionais, raciais, religiosas

8 Crime contra a humanidade são atos deliberados cometidos como parte de um ataque generalizado ou sistemático contra qualquer população civil. 
uma unidade humana e seus direitos universais fundamentais possuem na prática ações que se distanciam daquilo que the é fundamental.

Segundo pensadores pós-coloniais e decoloniais, como é o caso do egípcio Samir Amin (1994), o mundo contemporâneo é ideologicamente construído a partir da concepção de que a sociedade europeia seria superior em diferentes níveis, se tornando um parâmetro a ser seguido para as outras sociedades. A partir desse etnocentrismo eurocentrado, as vidas humanas na América Latina, África e Ásia são consideradas de menor importância e até descartáveis dentro de um plano global, em que conflitos armados são terceirizados, assim como condições desumanas de trabalho e a escassez de produtos essenciais para a vida.

Neste mesmo sentido, não só o presente de bilhões de homens e mulheres pelo mundo é descartado, como também o seu passado é visto como menos importante, o que reflete em uma pesquisa histórica e ensino de história deficientes, em que muitas vezes é eurocentrado, ou, até mesmo, ignorado.

Os caminhos percorridos pelos ruandeses nos mostram como uma visão etnocêntrica (centrada no homem europeu) leva à falência de um compromisso de uma humanidade com plena igualdade, tendo em vista que no genocídio de 1994 as Nações Unidas e a comunidade internacional pouparam esforços possíveis para evitar o genocídio de tutsis e hutus moderados.

Em meados da década de 1980, Ruanda entrou em uma profunda crise a partir da desestruturação de seu modelo econômico baseado em uma exportação quase que exclusiva de café. O governo do General Juvenal Habyarimana, que por anos se sustentava a partir da venda do café no mercado internacional, viu o preço do produto despencar no cenário econômico, diminuindo drasticamente a sua arrecadação, o que comprometeu e colapsou o pagamento da dívida externa. Tal cenário ampliou significativamente a pobreza em Ruanda, trazendo a escassez de alimentos e de emprego, em um processo semelhante ao ocorrido em boa parte do continente africano no decorrer da década de 1980, com o desenvolvimento e aprofundamento do neoliberalismo (BADI, 2008).

Segundo o intelectual congolês, Mbuy Kabunda Badi (2008), o advento de um capitalismo neoliberal na África resultou em um período de ampla instabilidade, dada a explosão da dívida externa e aumento da miséria, acarretando instabilidade política e conflitos armados, guerras civis, epidemias, episódios de extrema fome, e também genocídios, como foi o caso de Ruanda.

A instabilidade da Segunda República Ruandesa (1973 - 1994) na virada da década de 1980 e 1990 possibilitou o avanço da Frente Patriótica Ruandesa (RPF da sigla em 
francês), uma oposição armada ao governo de Habyarimana, que era composta por exilados ruandeses que estavam em Uganda. Os conflitos entre a RPF e o governo ruandês do Movimento Republicano Nacional pela Democracia e Desenvolvimento (MRND) perduraram de outubro de 1990 a julho de 1994 quando se encerra o genocídio que havia começado em abril de 1994.

Tal processo alimentou discursos extremistas, que entendiam a história ruandesa como sendo polarizada entre os grupos étnicos tutsis e hutus, ainda mais pelo fato de a RPF ser constituída majoritariamente por tutsis. Desse modo, grupos como o CDR, extremistas do MRND e o Hutu Power começaram a divulgar materiais contendo conteúdo de ódio, centrado em um nacionalismo hutu exacerbado, colocando o hutu como o único e verdadeiro ruandês. Em contraposição, os tutsis passaram a ser tratados publicamente por estes grupos como sendo estrangeiros em sua própria terra, cujo propósito era dominar os hutus a partir da RPF, de modo a caracterizar todos os tutsis como inimigos em potencial (STRAUS, 2006, p. 25).

A propaganda contra os tutsis constantemente coloca esses ruandeses como animais, principalmente inyenzi (baratas, do kinyarwanda), buscando retirar a sua própria humanidade ao animalizá-los, além de proclamar a necessidade de sua eliminação (FONSECA, 2015, p. 50). Esse processo ocorreu de maneira muito semelhante à propaganda nazista contra a população judaica que era comumente comparada a piolhos que deveriam ser eliminados (ARENDT, 1989).

Mesmo com a tensão crescente em Ruanda, e os indícios da possibilidade de um conflito generalizado, as Nações Unidas tomaram uma série de decisões que corroboraram para o desenvolvimento do genocídio, como é o caso da redução do contingente da UNAMIR e da valorização de operações para retirar de Ruanda apenas os europeus que estavam em perigo, explicitando o caráter etnocêntrico de suas preocupações.

Após a queda do avião presidencial do General Juvenal Habyarimana, no dia 6 de abril de 1994, grupos paramilitares, ${ }^{9}$ com apoio de parte significativa da população, deram início ao genocídio, assassinando entre 500 mil e um milhão de tutsis e de hutus moderados. O genocídio de Ruanda durou pouco mais de cem dias, mas a grande maioria das execuções ocorreram logo no primeiro mês, sendo realizadas principalmente a partir de facões. Durante estes cem dias, mesmo com imagens do extermínio rodando o mundo, a comunidade internacional pouco fez para encerrar o processo.

A história de Ruanda e o seu genocídio deveriam ser entendidos como uma história de toda a humanidade, assim como é o holocausto, e assim como tal, também poderia ser vista

9 Referimo-nos aqui à Interahamwe ligada ao MRND, e ao Impuzamugambi ligada à CDR. 
como uma história difícil, nos causando constrangimentos enquanto seres humanos. Assim, a história de Ruanda poderia ser mais trabalhada nas escolas no ensino da história, pois, conforme Adorno (1995, p. 119) nos escreve em "Educação pós Auschwitz":

\begin{abstract}
A exigência que Auschwitz não se repita é a primeira de todas para a educação. De tal modo ela precede quaisquer outras que creio não ser possível nem necessário justificá-la. Não consigo entender como até hoje mereceu tão pouca atenção. Justificá-la teria algo de monstruoso em vista de toda monstruosidade ocorrida. Mas a pouca consciência existente em relação a essa exigência e as questões que ela levanta provam que a monstruosidade não calou fundo nas pessoas, sintoma da persistência da possibilidade de que se repita no que depender do estado de consciência e de inconsciência das pessoas. Qualquer debate acerca de metas educacionais carece de significado e importância frente a essa meta: que Auschwitz não se repita.
\end{abstract}

Para evitar a repetição de acontecimentos como Auschwitz nos parece fazer necessário deixar ainda mais clara a importância do ensino de tais episódios, ainda que Adorno (1995) entenda que a necessidade de justificativa seria absurda, parece-nos que uma consciência histórica acerca de tais processos de extermínio ainda é insuficiente para impedir a sistemática repetição de Auschwitz.

Dessa forma, o ensino da história de Ruanda tem um grande potencial de gestar uma consciência histórica mais ampla, ajudando-nos a compreender os processos históricos que podem levar a extremismos quando se trata da hierarquização de divisões na humanidade. Mais do que isso, o genocídio de Ruanda teria o potencial de desnudar o excessivo etnocentrismo que concepções historiográficas possuem, dando um sentido mais sensível a histórias que nos parecem distantes.

\title{
História Difícil e a Formação da Consciência Histórica
}

A constatação de Peter Lee (2011), que todos mantemos relações incontornáveis com o passado, apresentada no artigo: Por que aprender História?, conduz reflexões acerca da Educação Histórica e do lugar das Histórias Difíceis na aprendizagem histórica. O passado está em todos os lugares, nos espaços públicos e privados, nas mídias, nos documentos, nos monumentos, nas comemorações, nos materiais didáticos, museus e arquivos, como parte integrante da vida humana, é mobilizado pela lembrança, pela memória individual e coletiva, pelas tradições incorporadas ao modo de vida e pela História, como ciência especializada.

Nas palavras de Michael Oakeshott (2003), filósofo crítico da história, a consciência do passado não ocorre pela negação do presente, mas por uma leitura do presente que chama o passado, nesse sentido, o passado é um entendimento do presente em termos de mudança, que se pode perceber, registar e conservar. 
Assim, o passado e o futuro emergem de leituras moduladas no presente, que tornam as outras dimensões temporais inteligíveis. "Então, tanto o futuro quanto o passado emergem apenas em uma leitura do presente; e um futuro ou um passado em particular estão qualificados a serem evocados a partir de um presente em particular, e são casualmente relacionados ao presente em particular a partir do qual podem ser evocados [...]" (OAKESHOTT, 2003, p. 52).

O pensamento de Oakeshott (2003) reconhece o passado como elemento constituinte da realidade presente, tal entendimento abre a possibilidade para compreensão das relações, influências e sentidos do passado no presente. Os sentidos atribuídos à relação passado e presente dependem essencialmente do tipo de experiência passada e da qualidade da interpretação dessa experiência temporal.

Acontecimentos específicos tais como guerras, genocídios e catástrofes que atingem grupos e sociedade permanecem influenciando e significando o presente, como fardo carregado pelas novas gerações, sua força de permanência se deve ao seu caráter traumático, no entanto, a relação difícil com o passado está diretamente ligada à natureza da sua interpretação, em outras palavras, os sentidos estabelecidos aos eventos traumáticos dependem da perspectiva empregada, por exemplo, se isso ocorre pela memória individual ou coletiva matizada, em grande medida, pelo senso comum ou se acontece pela via da tradição sedimentada no modo de vida ou pela ainda pela ciência da História, universo dos historiadores, os quais manipulam um determinado vocabulário e métodos de investigação que permitem uma leitura específica do passado.

Nesse universo de preocupações insere-se as discussões da chamada História Difícil ou Burdening History e suas implicações para aprendizagem histórica no ambiente escolar. Bodo von Borries (2016) sugere algumas definições, a expressão História Difícil refere-se às histórias amargas, tristes, pesadas e traumáticas, muitas vezes ocultadas e geradoras de sentimentos culpa, responsabilidade, vergonha e luto ao longo do tempo.

O sentimento de culpa não envolve punição individual ou coletiva, a atribuição de culpa a pessoas inocentes não envolvidas ou gerações posteriores é injusta e viola os direitos internacionais e humanos, mas significa levar em conta a relação com determinados eventos do passado, como ressalta Bodo von Borries (2016, p. 34):

Isso não implica que os membros das gerações posteriores nascidos em um país onde foram cometidos crimes políticos contra a humanidade (genocídios, por exemplo) são completamente desconectados de qualquer relação especial com o passado, ou não estão envolvidos de forma diferente do que qualquer outro lugar do mundo. 
As pessoas ou sociedade não herdam a culpa por um crime, mas herdam as consequências e os custos de um crime cometido no passado, isso chama responsabilidade. O sentimento de culpa carregado sobre novas gerações dificulta o trabalho histórico em sala de aula.

Com relação à vergonha, é sentimento muito forte, a vontade de evitá-la pela negação e recusa do crime também é muito forte, algumas reações, como ocultamento de acontecimentos, só podem ser compreendidas como uma tentativa de evitar a vergonha, "[...] isto inclui aproximações e distanciamentos, ao mesmo tempo, na relação presente e passado" (SCHMIDT, 2017, p. 16).

A respeito do sentimento de luto relacionado a crimes graves cometidos no passado, como, por exemplo, o Holocausto e o Genocídio de Ruanda, Bodo von Borries (2016) se pergunta quais elementos constituem o luto, no caso da história, Rüsen (2009, p. 200-201) ensaia uma resposta para essa questão:

\begin{abstract}
À primeira vista, a história nada tem a ver com o luto. O luto é emocional e relacionado a perdas recentes. A história é cognitiva e relacionada a um passado remoto. Mas essa impressão suscita equívocos, porquanto história e luto têm algo de essencial em comum: ambas são procedimentos da memória e comprometidas com a lógica de geração de sentido.
\end{abstract}

Os sentimentos de culpa, responsabilidade, vergonha e luto carregados pelas novas gerações de lugares que viveram a experiência de crimes hediondos dificulta o trabalho com as Histórias Difíceis em sala aula. Conforme esclarece Bodo von Borries (2016, p. 32), "a aprendizagem de casos afirmativos de heroísmo e glória/orgulho parece mais fácil, mas experiências negativas de danos e culpa/vergonha (ou ambos) são muito mais difíceis".

Com intenção de apontar caminhos metodológicos para superação das dificuldades de trabalho com História Difíceis no ensino de História, Borries (2016, p. 40) propõe uma Educação Histórica na perspectiva da "reconciliação histórica", cuja principal questão:

\footnotetext{
[...] é mover-se em direção ao outro e continuar juntos pelo mesmo caminho. Mas isso não é nada fácil; exige algumas pré-condições mentais: tomar distância do passado sem esquecê-lo, não permitindo que o passado determine completamente o presente, olhando para as condições e possibilidades de um futuro comum.
}

Na proposta do autor, aprender história, à luz de História Difíceis, envolve processos cognitivos, mas também aspectos de emoção, estética e julgamentos morais. Com base no pensamento de Borries, Schmidt (2017, p. 25-26) considera que "[...] há uma estrada a percorrer em direção a uma educação histórica que contribua para a formação da consciência histórica de nossos jovens e nossas crianças a partir da compreensão do 
presente à luz das controvérsias do passado". A pesquisadora toma como objetivo central da aprendizagem histórica a formação da consciência histórica dos jovens e crianças.

$\mathrm{Na}$ perspectiva de Rüsen (2001), a consciência histórica relaciona por meio de operações mentais o passado, o presente e o futuro, numa mesma estrutura temporal, a qual fornece sentido histórico à vida humana no tempo, ou seja, o resultado do trabalho mental da consciência histórica é a constituição de sentidos históricos, que significa a articulação dimensões temporais do passado, presente e futuro, numa estrutura temporal de continuidade.

Há uma experiência comum do tempo, a qual pode ser chamada de contingência, que significa que a vida humana é marcada a todo momento por sentimentos de ruptura, acontecimentos inesperados, catástrofes, guerras, acidentes e esperanças frustradas. A mudança temporal vivida e sofrida como instabilidade carece de ressignificação no curso do tempo para que as ocorrências contingentes se tornem plenas de sentido histórico para continuidade das atividades humanas cotidianas (RÜSEN, 2006).

A busca de sentido histórico para as mudanças que desestabilizam a vida humana é a "mola propulsora" da consciência histórica. As contingências que atingem os homens e mulheres cotidianamente precisam ser compreendidas, recorrendo-se às experiências do passado que quando interpretadas orientam a vida prática pela atribuição de sentido histórico. O exercício de interpretar a experiência do passado para compreender o presente e perspectivar o futuro de modo a orientar as ações na vida prática pode ser caracterizado como um processo de aprendizado histórico.

Assim, a aprendizagem histórica se estabelece com a formação da consciência histórica, isso traduz-se em um aumento da apreensão da experiência do passado, da capacidade de interpretação, da experiência do tempo e da capacidade de se orientar na vida prática, a partir da compreensão do presente por meio da interpretação das experiências vividas no passado. Nessa direção, a função da aprendizagem histórica é proporcionar orientação temporal à vida prática, por intermédio das operações essenciais da consciência histórica. A orientação temporal da vida prática ocorre em dois sentidos: externa e interna. A orientação temporal externa relaciona-se à práxis e a interna à formação da identidade histórica.

A consciência histórica pelos processos de aprendizagem cumpre importante função cultural: expressar e delimitar a identidade na perspectiva temporal. Ela circunscreve o domínio da vida de uma pessoa, os aspectos familiares e comuns do mundo próximo e também a relação com outros no mundo, "[...] que frequentemente é um 'outro mundo', e como tal um mundo estranho" (RÜSEN, 2009, p. 173). A formação de identidade com 
perspectiva temporal é uma forma de resistência as mudanças que atingem o indivíduo e o mundo, um confronto em busca de superação da experiência frequente de alteração do itinerário planejado, que ameaça a identidade, a familiaridade consigo mesmo e com o mundo. "A mudança provoca um esforço mental para manter o mundo e o 'eu' familiares ou para readquirir esta familiaridade nos casos de experiências de transformações extraordinariamente perturbadoras" (RÜSEN, 2009, p. 173), como, por exemplo, guerras, genocídios e catástrofes. A identidade histórica é um ganho cognitivo no enfrentamento das transformações sofridas no percurso da vida, essa conquista é produzida pela consciência histórica, por meio das relações entre passado, presente e futuro, que geram sentido histórico para experiências humanas.

Os sujeitos, pela identidade histórica, estabelecem fronteiras com os outros e ressaltam sua alteridade nas dimensões locais e temporais de um mundo comum, no qual buscam estabelecer a diferença em relação aos outros como estratégia de consolidação da identidade.

Nesse processo, cada modo de vida carrega valores, perspectivas positivas e preferências normativas, que servem como elementos de distinção, e os aspectos negativos e perturbadores são imputados aos outros. Essa caraterística, Rüsen (2009) denomina etnocentrismo e considera esse aspecto quase inerente à identidade humana. $O$ etnocentrismo estabelece uma relação assimétrica entre o "eu" e o "outro", entre a identidade e a alteridade, e torna a memória histórica controversa e propensa aos conflitos, "[...] pois o reforço da identidade do grupo que irá encontrar apoio entre seus membros será negada por aqueles que estiverem além de suas fronteiras e que não se reconhecem nesses quadros temporais aprovados pelo primeiro" (RÜSEN, 2009, p. 174).

\section{Análise de Conteúdos de Web}

Para analisarmos o ensino de História sobre Ruanda, particularmente, os aspectos etnocêntricos e controversos do episódio conhecido como genocídio de Ruanda optou-se pela avaliação de sítios da web direcionados à divulgação de conteúdos históricos, a escolha torna-se relevante devido ao crescente uso da internet com fins educacionais, muitas crianças e jovens acessam a rede como parte das suas atividades escolares e também os professores a tem utilizado na organização e na prática das aulas, como atestam as pesquisas de Cláudia Senra Caramaz (2014) e Jackes Alves de Oliveira (2016), as quais problematizam as relações entre ensino de História e as novas tecnologias da informação e comunicação. 
Cláudia Senra Caramez (2014), na dissertação: "A aprendizagem histórica de professores mediada pelas tecnologias da informação e comunicação: perspectivas da educação histórica", investigou as relações de experiência de aprendizagem histórica de professores da rede municipal de Curitiba-PR mediadas pelas novas tecnologias da informação e comunicação, no que diz respeito ao uso de fontes históricas primárias e secundárias encontradas na Web. O interesse principal da investigação concentrou-se na indagação acerca da possibilidade de os professores de história aprenderem história por meio dos documentos históricos alocados na Web. O trabalho empírico apontou que os professores no contato com fontes históricas oriundas da Web estabeleceram novas relações de aprendizagem histórica, perceberam a possibilidade de outras formas de aprender história e, consequentemente, novas maneiras de ensinar História.

Na dissertação: "Educação histórica e aprendizagem da 'história difícil' em vídeos do youtube", Jackes Alves de Oliveira (2016), situado no campo investigativo da Educação Histórico, pesquisou as aprendizagens históricas mobilizadas por professores e alunos do Ensino Fundamental II, que assistiram a vídeos do Youtube sobre a Ditadura Militar no Paraná. Esse acontecimento da história brasileira foi entendido como uma História Difícil, na perspectiva de Borries (2016) e Schmidt (2015). De modo amplo, a investigação apontou que contato com os vídeos do Youtube disponibilizados possibilitou a aquisição de algo que não se sabia ou a ampliação de assuntos já conhecidos, bem como, dinamizou a aprendizagem e favoreceu a expansão de conteúdos.

Nesse panorama investigativo buscou-se compreender os sentidos históricos dos conteúdos acerca do genocídio de Ruanda que circulam na internet e as possíveis implicações para aprendizagem histórica. $\mathrm{Na}$ atualidade, análises desse tipo tornam-se cada vez mais relevantes, pois, como alerta Peter Lee (2006, p. 147) "a História é cercada de concorrentes que declaram produzir bons cidadãos críticos ou pensadores críticos", tais como as mídias e redes sociais.

Ao realizarmos o levantamento de sítios que trabalham ou disponibilizam trabalhos acerca do genocídio de Ruanda, dois sítios administrados pela empresa Uol ganharam destaque: Uol Educação ${ }^{10}$ e Brasil Escola. ${ }^{11}$ Também realizamos um levantamento de vídeos no canal do Youtube para entrarmos em contato com o tipo de material que seria o mais veiculado pelo sítos de compartilhamento de vídeos.

No caso do sítio Brasil Escola, encontramos uma página intitulada "A Guerra Civil em Ruanda" (SILVA, 2017) na sessão de "História Geral" em que é disponibilizada para o 
professor, ou outros interessados, uma série de informações substantivas que envolvem a história ruandesa, principalmente a história recente mais diretamente envolvida com o genocídio de 1994. As informações disponíveis na página foram escritas pelo historiador Daniel Neves Silva.

Já na página do Uol Educação, encontramos uma página com o mesmo nome "Guerra Civil Ruandesa" (SILVA, 2007), no entanto este link não possui informações substantivas, mas sim uma proposta de atividade para ser trabalhada em sala de aula buscando uma reflexão que envolve o filme "Hotel Ruanda". A proposta de atividade foi escrita pela historiadora Érica Alves da Silva.

Ao desenvolver o contexto histórico que envolve a Guerra Civil Ruandesa e o próprio genocídio de Ruanda em 1994 de maneira substantiva, o historiador Daniel Silva divide, por meio do sítio Brasil Escola, a sua argumentação em quatro partes: Uma Breve Introdução; as Raízes da Rivalidade entre Tutsis e Hutus; Juvenal Habyarimana e a Guerra Civil e $O$ Genocídio Ruandês.

Em seu parágrafo introdutório, já podemos observar que a argumentação apresentada se demonstra centrada em um conflito dualista entre tutsis e hutus, no qual a Guerra Civil Ruandesa "tomou proporções de genocídio étnico quando hutus organizaram milícias e realizaram ataques contra os tutsis" (SILVA, 2017). A excessiva dualidade entre tutsis e hutus, enquanto grupos étnicos rivais não corrobora com uma perspectiva crítica acerca do genocídio ruandês, tendo em vista que a complexidade de tal episódio é apagada por versão simplista. É importante apontar que o genocídio ruandês não pode ser caracterizado como um mero acúmulo de ódio étnico entre dois grupos rivais, tendo em vista que milhares de hutus (tidos como moderados) também foram assassinados por hutus radicalizados, desșa forma a dualidade tutsi/hutu não é o melhor caminho para se estudar o conflito ocorrido em Ruanda.

A concepção de um conflito étnico ou até tribal está permeada por um ensino com características etnocêntricas e corrobora com um ensino de História que marginaliza e desvaloriza o sujeito histórico africano, tendo em vista que esses são postos como incapazes de mediar a sua esfera pública para além da sua esfera étnica privada, em uma perspectiva que provoca uma relação assimétrica entre o "eu" e o "outro". Dessa forma, a relação entre grupo étnico e política dentro do ensino de História de Ruanda, e também do continente africano, necessita de um maior zelo para que um reducionismo não corrobore com a visão de um suposto continente "atrasado" frente aos demais.

Ao desenvolver As Raízes da Rivalidade entre Tutsis e Hutus, o autor novamente supervaloriza as construções étnicas, mas mais do que isso, coloca a rivalidade entre tutsis 
e hutus como algo intrínseco da cultura local, observando o contexto pré-colonial a partir de uma concepção colonizada, em que as configurações sociais dos Banyarwandas passa a ser entendida com uma interpretação equivocada, tendo em vista que as relações sociais entre tutsis e hutus em sua sociedade pré-colonial eram compostas por uma série de costumes e tradições que mediavam lugares sociais e tarefas dentro de uma complexa rede de favores e deveres, que poderia ter variações em sua configuração. É importante destacar que o enquadramento histórico de sociedades pré-coloniais não europeias também se configura como uma importante ferramenta etnocêntrica, a qual, quando envolvida no ensino da história, transmite uma visão de mundo homogênea dentro de parâmetros da história europeia.

Ainda dentro dessa perspectiva, para o autor, a colonização europeia teria apenas acentuado a rivalidade já existente, o que aponta para uma concepção histórica de Ruanda com baixa criticidade frente a violência do colonialismo europeu no continente africano durante o século $\mathrm{XX}$, algo necessário para o desenvolvimento de concepção histórica não eurocentrada.

O excesso de polaridade entre tutsis e hutus também é o cerne da discussão sobre a guerra civil ruandesa, na qual o autor apresenta a Frente Patriótica Ruandesa como sendo uma mera organização tutsi, o que não condiz com a formação de tal organização política e militar, tendo em vista que grupos de hutus exilados também faziam parte da RPF. A construção de uma visão de uma RPF exclusiva de tutsis, além de corroborar com a visão excessivamente étnica da história ruandesa, também se vincula diretamente ao próprio discurso extremista do Poder Hutu, que buscava convencer a população local de que a RPF seria uma organização tutsi, com o intuito de reforçar o discurso genocida.

Já na página divulgada pela Uol Educação, o que encontramos é uma proposta de plano de aula com atividade vinculada ao filme "Hotel Ruanda" (1994) de Terry George. A proposta, de autoria da historiadora Érica Silva, tem como principal objetivo a construção de uma reflexão sobre a Guerra Civil Ruandesa e o genocídio de Ruanda a partir de uma possibilidade de sensibilização dos alunos frente a temática.

Para a autora, "diante das atrocidades ali ocorridas e da necessidade do reconhecimento da história da África, sua riqueza cultural e seus problemas na atualidade" a história de Ruanda torna-se um conhecimento necessário aos estudantes dentro das aulas de história, de tal modo que o caminho proposto para abordar tal complexa temática é pela discussão do filme "Hotel Ruanda". ${ }^{2}$

12 O filme retrata os esforços de Paul Rusesabagina que durante o genocídio de Ruanda abrigou mais de 1200 refugiados no Hotel des Milles Collines no qual era gerente. Direção de George Terry, lançado em 2005. 
A estratégia proposta por Silva consiste em um primeiro momento deixar "que seus alunos assistam ao filme sem que nenhuma colocação anterior seja feita" (SILVA, 2007), tal postura aparenta ter a função de trazer um choque aos alunos, dada a dramaticidade da película e a sensibilidade da temática, de modo a transmitir uma História Difícil aos estudantes, comovendo-os frente ao processo histórico enfrentado pelos ruandeses em uma questão que transcende questões de nacionalidade e territorialidade.

Segundo a estratégia traçada por Silva, após os estudantes assistirem ao filme, e já sensibilizados pela temática, o professor deveria perguntar "quais são suas impressões, se gostaram do filme, se conheciam a existência dessa guerra, por que acham que não conhecem, ou por que poucos conheciam" (SILVA, 2007). O intuito em tais perguntas parece, em um primeiro momento, valorizar o modo que a temática do genocídio de Ruanda é recebida pelos estudantes, em uma valorização do aspecto subjetivo ao perguntar por "impressões" ou se gostaram do filme, tal postura vai ao encontro da perspectiva de uma história difícil.

Por outro lado, ao mesmo tempo que se busca as percepções subjetivas dos discentes, as perguntas propostas em um segundo momento parecem querer denunciar o não conhecimento ou a falta de conhecimento sobre a história e o genocídio de Ruanda, o que pode ser entendido como uma possibilidade de denúncia do caráter etnocêntrico que existe na seletividade da escolha das temáticas históricas a serem discutidas pela sociedade (seja na indústria cultural, imprensa ou cotidiano), assim como as temáticas que são trabalhadas no ensino da história, em que o silenciamento de alguns sujeitos históricos e a não sensibilização com os seus processos históricos expressa uma sociedade excessivamente eurocentrada.

Essa postura de denúncia de alguns silenciamentos na história se faz presente nos objetivos do plano de aula propostos pela autora, em que a "percepção da relevância dos 'silêncios' na história [...] também faz parte do posicionamento dos sujeitos históricos”, ou seja, essa postura frente ao genocídio de Ruanda nos aponta para um posicionamento eurocêntrico em nossa sociedade.

Nossa última frente de análise corresponde ao material "Entenda o genocídio de Ruanda"13, uma animação de quase sete minutos veiculada no site do Youtube, e que possui mais de 55 mil visualizações, o que o torna o material sobre Ruanda em português mais visto do canal. A técnica do vídeo é a whiteboard animation, que ficou popular nas redes sociais e é realizada a partir de animações em cartolina branca, na qual um par de

13 Vídeo disponível no site: https://www.youtube.com/watch?v=aCx5xosJwxg, acesso em 27/09/2018. 
mãos constrói as imagens e símbolos no ritmo em que a história ganha a sua narrativa, se utilizando de mapas, fotos, bonecos desenhados, entre outras ferramentas didáticas.

O vídeo inicia com uma explicação geográfica acerca de Ruanda, seguida de apontamentos históricos substantivos acerca da sua construção, indicando principalmente os diferentes grupos que lá existem. É interessante notar que a animação busca não colaborar com a visão de que Tutsis e Hutus seriam inimigos históricos, colocando-os inclusive como grupos que possuíam diferentes relações sociais.

No entanto, a narração coloca um peso excessivo no colonialismo frente a história ruandesa, em que os belgas teriam "forçado uma rivalidade entre tutsis e hutus", utilizandose de uma "teoria das raças", dando um tom manipulativo a um paradigma do período. Essa postura de valorizar a ação dos colonizadores, por mais críticas que tais ações mereçam, pode, por outro lado, atribuir uma excessiva passividade aos homens colonizados, em que esses deixam de fazer a sua própria história, o que é bastante comum dentro de uma perspectiva etnocêntrica em que a Europa e o homem europeu tornam-se os grandes agentes históricos. O esvaziamento histórico dos ruandeses ainda é notável na medida do lapso histórico cometido pelo vídeo, em que ao término do colonialismo em Ruanda, os ruandeses são apresentados de maneira imediata à crise do final da década de 1980 e início dos anos 1990, com a sua Guerra Civil, como se o período anterior fosse um mero acúmulo de ódio étnico que explodiria com o genocídio em 1994.

Por outro lado, o vídeo se atenta mais ao próprio processo do genocídio com detalhes mais precisos acerca do conflito, apesar de colocar o genocídio como um massacre exclusivo de tutsis (enquanto que milhares de hutus moderados também foram mortos), e também de valorizar as intervenções estrangeiras, ou até mesmo a não intervenção (como é caso do vídeo explicar que os Estados Unidos não quiseram intervir, um dado bastante insignificante para uma explicação rápida). O vídeo também se atenta em divulgar a Ruanda pós-genocídio, se preocupando com seu processo político e os julgamentos ocorridos pelos tribunais internos denominados de Gacaca.

Apesar de algumas imprecisões o vídeo, a partir da música de fundo e da construção didática das imagens, consegue transmitir uma sensibilização acerca do genocídio, capaz de transformar esse processo histórico singular em uma questão próxima de todos nós, causando incômodo àqueles que o assistem. 


\section{Considerações Finais}

O ensino de Histórias Difíceis, como do genocídio de Ruanda, um acontecimento traumático que desafia a compreensão humana, oportuniza aprendizagens que promovam uma consciência histórica humanista, a superação do pensamento etnocêntrico, cujo horizonte cultural assenta-se na ideia de efetivar a identidade coletiva distinguindo o seu próprio povo de outros, tendo como face mais dramática e perversa, o uso do conflito como justificativa para preservação identitária.

A lógica do pensamento etnocêntrico aplicada à história está baseada numa relação assimétrica entre o bem e o mal, os valores positivos projetam a imagem histórica de si mesmo e os negativos moldam dos outros. "Tendemos a atribuir a maioria de valores positivos a nós mesmos e o contrário é verdadeiro no que se refere à alteridade dos outros" (RÜSEN, 2009, p. 175).

O pensamento histórico etnocêntrico potencializa a desumanização porque promove a distinção do grupo de pertencimento em relação aos outros, não reconhece os seus valores humanos nos outros, traça uma linha clara de separação do outro, considerado desigual.

O estudo das Histórias Difíceis, como o genocídio de Ruanda, oportuniza reconhecer as consequências do pensamento etnocêntrico, o qual rouba a qualidade de seres humanos considerados os outros, essa compreensão abre espaço para construção de um pensamento humanista amplo, que inclua e reconheça as diferenças culturais, como condição antropológica universal.

Nessa perspectiva, os conteúdos históricos acerca do genocídio de Ruanda presentes na Web, submetidos à crítica reveladora das narrativas etnocêntricas, podem contribuir com o ensino e aprendizagem dessa difícil história, a qual avilta nosso sentido de humanidade, mas, que ao mesmo tempo carrega o potencial para construção de um amanhã mais inclusivo e humano. 


\section{Referências}

ADORNO, Theodor W. Educação após Auschwitz. In: ADORNO, Theodor W. Palavras e sinais: modelos críticos 2. Petrópolis: Vozes, 1995. p. 119-138.

AMIN, Samir. Eurocentrismo: crítica de uma ideologia. Lisboa: Dinossauro, 1994.

ARENDT, Hannah. Origens do totalitarismo. São Paulo: Cia das Letras, 1989.

BADI, Mbuyi Kabunda. África em la globalización neoliberal: las alternativas africanas. Theomai: Estudios sobre Sociedad, Naturaleza y Desarrollo, Buenos Aires, n. 17, 2008.

BORRIES, Bodo von. Lidando com histórias difíceis. In: FRONZA, Marcelo; SCHMIDT, Maria Auxiliadora; NECHI, Lucas Pydd. Jovens e consciência histórica. Curitiba: W. A. Editores, 2016. p. 32-41.

CAMPOS, Paulo Fernando de Souza. Ensino, a história e a lei 10.639. História \& Ensino, Londrina, v. 10, p. 41-52, out. 2004.

CARAMEZ, Cláudia Senra. A aprendizagem histórica de professores mediada pelas tecnologias da informação e comunicação: perspectivas da educação histórica. 2014. Dissertação (Mestrado em Educação) - Programa de Pós-Graduação em Educação, Universidade Federal do Paraná, Curitiba, 2014.

COMPARATO, Fábio Konder. A afirmação histórica dos direitos humanos. São Paulo: Saraiva, 2003.

FONSECA, Danilo Ferreira da. África entre classes e etnias: África do Sul (1948-1994) e Ruanda (1959-1994). Saarbrücken: Novas Edições Acadêmicas, 2015.

HABERMAS, Jürgen. Bestialidade e humanidade: uma guerra na fronteira entre o direito e a moral. Die Zeit, Hamburg, v. 54, p. 1-8, 1999.

LEE, Peter. Em direção a um conceito de literacia histórica. Educar em Revista, Curitiba, n. esp., p. 131-150, 2006.

LEE, Peter. Por que aprender História? Educar em Revista, Curitiba, n. 42, p. 19-42, out./dez. 2011.

LEVENSON, Ellie. A shame on all humanity. The Guardian, London, 31 Mar. 2009. Disponível em: https://www.theguardian.com/education/2009/mar/31/rwanda-genocide. Acesso em: 27 set. 2018.

OAKESHOTT, Michael. Presente, futuro e passado. In: OAKESHOTT, Michael. Sobre a história e outros ensaios. Rio de Janeiro: Topbooks, 2003. p. 43-98.

OLIVEIRA, Jackes Alves de. Educação histórica e aprendizagem da "história difícil" em vídeos do Youtube. 2016. Dissertação (Mestrado em Educação) - Programa de PósGraduação em Educação, Universidade Federal do Paraná, Curitiba, 2016.

RÜSEN, Jörn. Como dar sentido ao passado: questões relevantes de meta-história. História da Historiografia, Mariana, n. 2, p. 163-209, mar. 2009. 
RÜSEN, Jörn. Historiografia comparativa intercultural. In: MALERBA, Jurandir (org.). A História escrita: teoria e história da historiografia. São Paulo: Contexto, 2006. p. 115-137.

RÜSEN, Jörn. Razão histórica: teoria da história: os fundamentos da ciência histórica. Brasília: Editora Universidade de Brasília, 2001.

SCHMIDT, Maria Auxiliadora. A educação histórica e o ensino da história difícil. In: GERMINARI, Geyso Dongley; GILLIES, Ana Maria Rufino. Ensino de história e debates contemporâneos. Guarapuava: Unicentro, 2017. p. 13-27.

SCHMIDT, Maria Auxiliadora. Aprendizagem da "burdening history": desafios para a educação histórica. Mneme: Revista de Humanidades, Caicó, v. 16, n. 36, p. 10-26, jan./jul. 2015. Disponível em: http://www.periodicos.ufrn.br/mneme/article/viewFile/8094/6124. Acesso em: 15 maio 2016.

SILVA, Daniel Neves. Guerra civil em Ruanda. In: REDE OMNIA. Brasil Escola. Goiânia, 30 out. 2017. Disponível em: https://brasilescola.uol.com.br/historiag/guerra-civil-ruanda.htm. Acesso em: 25 set. 2018.

SILVA, Érica Alves da. História geral: guerra civil em Ruanda. In: GRUPO FOLHA. UOL Educação. São Paulo, 20 nov. 2007. Disponível em: https://educacao.uol.com.br/planos-deaula/medio/historia-geral-guerra-civil-em-ruanda.htm. Acesso em: 25 set. 2018.

STRAUS, Scott. The order of the genocide: race, power, and war in Rwanda. Ithaca: Cornell University Press, 2006. 